\title{
El patrimonio documental como instrumento indispensable para la descripción disciplinar del patrimonio. Algunos ejemplos de tipologías en el Archivo Histórico Minero de Fundación Río Tinto (es.21049.ahmfrt)
}

Juan Manuel Pérez López ${ }^{a}$

${ }^{a}$ AHMFRT, Plaza Ernest Lluch s/n, 21660 Minas de Riotinto. archivohistoricoriotinto@telefonica.net

\begin{abstract}
Resumen
La explotación de las minas de Río Tinto por The Rio Tinto Company Limited fundamentalmente y otras compañias españolas (CEMRT, ERT, RTP, RTM, etc.), transformaron el territorio y lo convirtieron en un paisaje cultural con características propias. Por una parte, generaron un conjunto de instalaciones mineras que con el paso del tiempo cuando perdieron su funcionalidad, han sido recuperadas como parte integrante del patrimonio y como elementos para el desarrollo del turismo cultural. Y de otra, un conjunto de patrimonio documental que ha sido organizado, conservado y custodiado para la investigación histórica y cultural desde la creación del AHMFRT.

Pondremos de manifiesto la diversa tipología del patrimonio documental custodiado por Fundación Río Tinto y su incidencia en los distintos "patrimonios" (histórico, arqueológico, arquitectónico, tecnológico, antropológico, etc.) que se generaron con la explotación minera, de forma que permita una interacción de estudios interdisciplinares a partir del patrimonio documental como eje transversal. Así, incidiremos en la importancia de ir hacia una gestión integral del patrimonio minero, que afecta tanto a los actores como a los elementos del patrimonio. Para poner en valor un patrimonio documental olvidado al servicio de la reconstrucción del paisaje minero que nos muestra las huellas de un pasado industrial floreciente.
\end{abstract}

Palabras clave: minería, patrimonio, documentos, archivo, paisaje.

\begin{abstract}
The mining in Rio Tinto mostly by The Rio Tinto Company Limited and other Spanish companies (CEMRT, ERT, RTP, RTM, etc.), they changed the territory and turned it into a cultural landscape with its own characteristics. On the one hand, this activity generated a set of mining facilities that over time it have been recovered as part of the heritage and as elements for the development of cultural tourism, once they lost its functionality. On the other hand, it generated documentary heritage that has been organized, preserved and guarded for historical and cultural research since the creation of the AHMFRT.

This work is about highlighting the different typology of the documentary heritage guarded by the Rio Tinto Foundation and its impact on the different "heritage" (historical, archaeological, architectural, technological, anthropological, etc.) which were generated with mining, in a way that allows interaction of interdisciplinary studies based on documentary heritage as a transversal axis. It will be emphasized the importance of going towards to an integral management of the mining heritage, which affects both the people responsible for it and the elements of the heritage. This way it will be valued a forgotten documentary heritage at the service of the reconstruction of the mining landscape that shows us the traces of a flourishing industrial past.
\end{abstract}

Keywords: mining, heritage, documents, archive, landscape. 


\section{Introducción}

El patrimonio documental minero es un instrumento ideal para la explicación de la historia más cercana, ya que las industrias extractivas que los generan están fuertemente localizadas en una comarca, región, etc., y sus series documentales están directamente relacionados con sus habitantes y con el devenir económico de toda una comarca. Aunque en este caso, la historia de las minas de Río Tinto, con la llegada de la RTCL trasciende con mucho el ámbito local convirtiéndose en un referente de la industria nacional e internacional por lo que significó en la producción mundial de cobre y piritas. Además, al ser un patrimonio muy vinculado a la sociedad que lo genera, perciben el Archivo como custodio y depositario de su propio pasado, por lo que se reconocen e identifican en él como parte de una misma comunidad minera. Las fuentes documentales del Archivo Histórico Minero de la Fundación Río Tinto (AHMFRT) representan una carga socio-afectiva para la comarca y a través de ellas se produce un proceso de concienciación sobre la importancia del patrimonio minero, poniendo de manifiesto los aspectos positivos del patrimonio industrial en la actualidad como factor endógeno de desarrollo local (Jiménez, 1997).

La explotación de las minas de Río Tinto generaron en su día un conjunto de documentos, que han sido organizados, conservados y custodiados para la investigación histórica y cultural en el AHMFRT, pero también existe un conjunto de instalaciones mineras que con el paso del tiempo, cuando perdieron su funcionalidad y una vez afectadas por la obsolescencia, algunas de ellas han sido recuperadas como parte integrante del patrimonio y como elementos para el desarrollo del turismo cultural, mientras otras están en un estado de conservación lamentable o han desaparecido definitivamente. Este patrimonio documental, el patrimonio industrial conservado, y las huellas de la minería en el paisaje, son los únicos instrumentos disponibles para la explicación de este pasado histórico industrial, por lo que se ha convertido en un patrimonio indispensable no sólo para el estudio histórico de la minería sino, en muchos casos, como único vestigio patrimonial de la "cultura minera". Por todo ello, creemos imprescindible su estudio como elementos del patrimonio minero y su puesta en valor a partir de su investigación, restauración, conservación y difusión.

En cuanto a la Didáctica del patrimonio, el AHMFRT, a pesar de ser un ámbito no formal, puede ser un "espacio educativo" ideal para efectuar prácticas y aprender a través de los documentos, por la variedad y carácter sencillo de las innumerables series que revelan el patrimonio de una comarca y por la relación directa de la historia que emana de ellos y los ciudadanos de la comarca.

Los documentos son los instrumentos más idóneos para la reconstrucción de este pasado histórico y del proceso productivo. A través de ellos obtenemos información relativa a la institución, dirección, ofícina técnica (proyectos, evolución tecnológica), personal (mercado de trabajo, salarios, relaciones comerciales, aprovisionamiento, patrimonio (concesiones mineras, propiedades), servicios médicos, seguridad e higiene, contabilidad, producción, geología, etc. El Archivo nace, así, de forma involuntaria, como reflejo documental de una actividad de gestión. La empresa crea su archivo de forma natural, según avanza la gestión de los asuntos. Desde su creación en 1990, el AHMFRT se ha consolidado como institución especializada en su custodia y habilitación y atiende labores tan importantes como las de difusión e investigación, que es el objeto fundamental de todo archivo, convirtiéndose en un referente de archivo histórico de empresa en nuestro país, como acredita las publicaciones de muchos trabajos que tienen como base de investigación el AHMFRT, de forma que incluso ha sido reconocido expresamente por el Ministerio de Cultura como de gran interés para la historia del siglo XX.

\section{Tipologías y series documentales del AHMFRT}

El patrimonio documental se nos antoja como un patrimonio indispensable para el estudio interdisciplinario de los distintos tipos de patrimonio, tanto mueble como inmueble, material como inmaterial. Debemos conservar en la memoria colectiva todo este patrimonio industrial que emana de la documentación generada por las distintas compañías que explotaron las minas y que está custodiada y conservada en AHMFRT. Si ya no podemos restaurar algunos bienes, sí se puede difundir también la cultura minera a través del patrimonio minero desaparecido, a través de algún plano, foto, información, etc., conservados en el archivo. Por todo ello el AHMFRT se ha convertido en una institución fundamental de preservación del patrimonio minero. A partir de él estamos creando un Centro de Interpretación Histórica de la minería de Riotinto. 
No se trata pues de conservar simplemente los restos materiales aislados, el objetivo fundamental es la explicación del proceso histórico en un territorio interactuado por las comunidades que se asentaron en él, con la recuperación patrimonial del proceso industrial que se produjo en la comarca como consecuencia de las compañías atraídas por la riqueza minera. El conocimiento de los procesos, la evolución tecnológica y su imbricación en el territorio, y la participación social en este proceso (Sobrino, 1996).

El fondo Minas de Río Tinto fue generado, en primer lugar, por The Rio Tinto Company Limited, que explotó las minas desde 1873 hasta 1954, cuando se produce la nacionalización de las minas, y desde entonces por compañías españolas como Compañia Española de Minas de Rio Tinto, Rio Tinto Patiño, Explosivos Rio Tinto, Rio Tinto Minera, etc., que constituyen el grueso de la documentación del AHMFRT. Además, están depositados otros fondos como los correspondientes al Instituto Seamens, Sánchez Mora, Minas de Peña del Hierro, Sociedad Minera de Nerva, Mina de Concepción, Sociedad Francesa de Piritas de Huelva y Minas de Herrerías, que prácticamente hasta su creación no habían tenido ningún plan para su conservación y organización, ni ningún tratamiento archivístico adecuado por parte de ninguna institución pública o privada especializada.

En la actualidad hay unas 35.000 unidades de instalación documentales dispuestas para la investigación, aunque hay que advertir que los trabajos de organización siguen desarrollándose, por lo que las unidades de consulta se verán incrementadas en un futuro. Veamos pues algunos ejemplos de tipologías y series documentales del AHMFRT para la heurística del patrimonio minero, que permiten la identificación del patrimonio.

\subsection{Documentación textual}

Son numerosas las series y documentos que informan de la industrialización de Riotinto, que recrean fielmente la situación y evolución del patrimonio minero, a pesar de que muchas veces su estado de conservación es lamentable, a veces desaparecido, por lo que los documentos son los únicos instrumentos garantes del conocimiento tecnológico, de los sistemas y de los procedimientos empleados para la explotación en el pasado. Además de su función informativa y didáctica, que analizaremos después, a través de los numerosos documentos textuales se puede recrear el patrimonio minero abandonado e incluso desaparecido para su incorporación en la actualidad a los proyectos de patrimonialización, por lo que los documentos se pueden convertir en instrumentos para el rescate del patrimonio minero (Pérez, 2003).

Vamos a describir algunas series documentales que ejemplarizan la funcionalidad documental en relación con el patrimonio industrial en todas sus acepciones: tecnológico (Tabla 1), arquitectónico (Tabla 2), arqueológico (Tabla 3), etnográfico, histórico, etc. Para una información más exhaustiva del fondo Minas de Riotinto se puede consultar el catálogo de instrumentos de descripción del AHMFRT (Pérez, 2008), y para el resto de fondos la consulta de sus instrumentos de descripción se encuentra en la sede del Archivo. Sólo destacaremos, a modo de ejemplo, algunas series relevantes en relación con el análisis de los distintos "patrimonios".

Tabla 1. Patrimonio tecnológico, científico y territorial

\begin{tabular}{clrc}
\hline Clasif. & \multicolumn{1}{c}{ Serie } & Legajos & Fechas \\
\hline 1.6 .3$. & Estudios, informes generales e investigación. & $1712-1716 /$ & $1914=1991$ \\
1.6.4.2. & Proyectos Técnicos. & $1801-1803 /$ & $1905=1998$ \\
1.6.4.4.1. & Planes de Labores de Minas & $1858-1859 / 1899-1900 / 2137 / 2287-$ & $1942=1976$ \\
& & $2304 / 2641$ & $1952=1982$ \\
1.6.4.4.2. & Planes de Labores de Aguas Cobrizas & $1718-1745 / 1804 /$ & $1945-1971$ \\
1.6.4.4.3. & Planes de Labores de Canteras & $1860-1861 / 2305-2367 / 2642$ & $1914-1985$ \\
1.6.5.1. & Centro de documentación e información. & $2369-2370$ & $1873=1968$ \\
1.6.9.1. & Mina Chaparrita (Nerva) & $2371-2372$ & $1898=1978$ \\
1.6.9.14. & The Peña Copper Mines y Compañía Nacional de Piritas. & $2373 / 2646$ & $1881=1995$ \\
1.6.9.33. & Exploración Minera & $1746-1754 /$ & $1883=1971$ \\
2.10.4.1. & Expedientes de las Demarcaciones mineras: planes de & $1901 / 2152 / 2374 / 2646$ & $1932=1974$ \\
2.10.4.2. & Registro de Minas y Permisos de Investigación. & 2379 & \\
\hline
\end{tabular}


El patrimonio documental como instrumento indispensable para la descripción disciplinar del patrimonio. Algunos ejemplos de tipologías en el Archivo Histórico Minero de Fundación Río Tinto (es. 21049.ahmfrt)

Tabla 2. Patrimonio arquitectónico

\begin{tabular}{clcc}
\hline Clasif. & \multicolumn{1}{c}{ Serie } & Legajos & Fechas \\
\hline 1.6.4.3. & Central de la Construcción y Surtido de aguas & $1900 / 2368 / 2627-2628 / 2643-2645$ & $1926=1982$ \\
2.10 .1$. & Registro general de propiedades & Lib. 992-993/1993 & $1873-1982$ \\
2.10 .3 .3$. & Inventario de casas. & 1992 & 1950 \\
2.10 .3 .5 .1$. & De edificios de Huelva y Tráfico Mina & $2049 / 2470$ & $1956=1973$ \\
2.10 .3 .5 .2$. & Del Ferrocarril Riotinto-Huelva y Ramales & $2470 / 2680$ & 1968 \\
\hline
\end{tabular}

Tabla 3. Patrimonio arqueológico

\begin{tabular}{|c|c|c|c|}
\hline Clasif. & Serie & Legajos & Fechas \\
\hline \multirow[t]{3}{*}{$100-\mathrm{B}-9$} & $\begin{array}{l}\text { School of archaeology and Prehistory and a Museum at } \\
\text { Niebla. }\end{array}$ & Documento electrónico. DVD-L-47 & $1828-1935$ \\
\hline & $\begin{array}{l}\text { Excavations at Niebla in the Province of Huelva Spain. by JP } \\
\text { Droop. Extract form The annals of Archcology and } \\
\text { Anthropology Vol XII nos } 3 \text { and } 4 \text {. report with Photographs. } \\
\text { ( } 2 \text { copies). }\end{array}$ & & \\
\hline & $\begin{array}{l}\text { Copies of the Madrid mail a fortnightly English newspaper. } \\
\mathrm{N}^{\mathrm{o}} 12,13,14,15,17 \text { and } 24 \text { containing extracts from "the } \\
\text { fortress of Niebla and Gibraltar in Spanish History and } \\
\text { archaeology by major burchell. }\end{array}$ & & \\
\hline $100-B-14$ & Rueda hidráulica Romana. & Documento electrónico. DVD-L-47 & 1886 \\
\hline $100-B-22$ & Rueda hidráulica Romana. & Documento electrónico. DVD-L-47 & 1886 \\
\hline 100-B-55 & $\begin{array}{l}\text { Archaeological Excavations at Niebla by Mr Wishart and } \\
\text { Professor Droop. }\end{array}$ & Documento electrónico. DVD-L-47 & $1892-1926$ \\
\hline $100-B-55$ & $\begin{array}{l}\text { Lucernas Mineras de Riotinto. Highlighting Shafts at the Rio } \\
\text { Tinto Mines Publisher by Archivo Español de Arqueologia } \\
\text { by J M Luzon, } 14 \text { Pages Illustrated. }\end{array}$ & Documento electrónico. DVD-L-47 & 1967 \\
\hline $100-B-57$ & Roman Water Wheels and Timbering. & Documento electrónico. DVD-L-47 & 1905 \\
\hline $100-B-63$ & $\begin{array}{l}\text { Roman Water Wheel - Drawing of the Wheel Discovered at } \\
\text { North Lode. }\end{array}$ & Documento electrónico. DVD-L-47 & 1886 \\
\hline
\end{tabular}

Documentos que atestiguan y permiten el estudio a posteriori de la transformación antrópica del paisaje y de la relación del entorno territorial y sus pobladores (paisanaje). Podemos encontrar series de transportes (ferrocarril, camiones, etc.), repoblación forestal, tierras y ganado, montes, terrenos urbanos y rústicos, Bellavista, Huelva, Punta Umbría, huertos, concesiones mineras, permisos de investigación, informes de minas, servicios, economatos, etc. Se conservan también los proyectos técnicos de las construcciones e instalaciones propias de la actividad minera que se llevaron a cabo para la obtención y transformación del mineral, como proyectos de arranque, sistemas de explotación (pozos y cortas), explosivos, fundición, cernido, trituración, concentrador, lavaderos, cargadoras, molienda, flotación, canteras, sistemas de transportes, estaciones eléctricas, suministro de agua, obras, y otros muchos. En fin, asuntos tan variados que pueden ser objeto de análisis desde muchas disciplinas.

Y por supuesto un patrimonio etnográfico e inmaterial marcado por las relaciones paternalistas que la RTCL estableció con sus obreros y la comarca, las relaciones institucionales, sociales y políticas, escuelas, cementerios, personal, deportes (fútbol, golf, tenis, etc.), viviendas, taller de bordados, oficios, etc.

En conclusión, en el Archivo también podemos obtener información sobre los usos, representaciones, expresiones, conocimientos y técnicas, junto con los instrumentos, objetos, artefactos y espacios culturales que fueron inherentes a una comunidad minera, que forman otra parte importante de su patrimonio cultural. 


\subsection{Documentación fotográfica (En imagen)}

La documentación en imagen ilustra todos estos tipos de "patrimonios". En la actualidad tenemos catalogadas más de 12.000 fotografías. A partir de mediados del siglo XIX la fotografía se va a convertir en el documento más fidedigno para la captación de la realidad. Y como tal será un excelente instrumento para documentar el patrimonio industrial, como testimonio tanto de los edificios e instalaciones arquitectónicas e ingenieriles, como de la vida cotidiana.

El AHMFRT cuenta con fotografías datadas ya desde 1875, pero las fotos más antiguas con sus autorías constatadas son las colecciones de Hauser y Menet y de Jean Laurent, atraídos por la espectacular industria minera y las imponentes arquitecturas del hierro de la provincia de Huelva a finales del siglo XIX (Fig. 1). De esta firma, formaban parte de los fondos del AHMFRT diez positivos originales datados entre 1892 y 1896, que muestran fielmente los lugares de trabajo en Riotinto (Corta del Lago, San Dionisio, teleras, Filón Sur, Canaleos), los pueblos (Rio Tinto Pueblo), edificios (Hotel Colón) y el ferrocarril según sus propios títulos impresos en la misma fototipia. Pero recientemente se ha recibido una donación de D. Pedro Real de un álbum con 124 fototipias de Hauser y Menet de unas medidas en torno a 21x15,5 cm, con una lámina doble, que representan el muelle de la Compañía de Rio Tinto en Huelva de $42 \times 14 \mathrm{~cm}$. En concreto es el Tomo 1 de la España Ilustrada, que incluye imágenes de Andalucía, Alicante y Cartagena, donde aparecen 14 fototipias relacionadas con la compañía de Rio Tinto, con imágenes de las minas y el muelle de Huelva, que también se editaron a partir de 1892 como postales individuales.

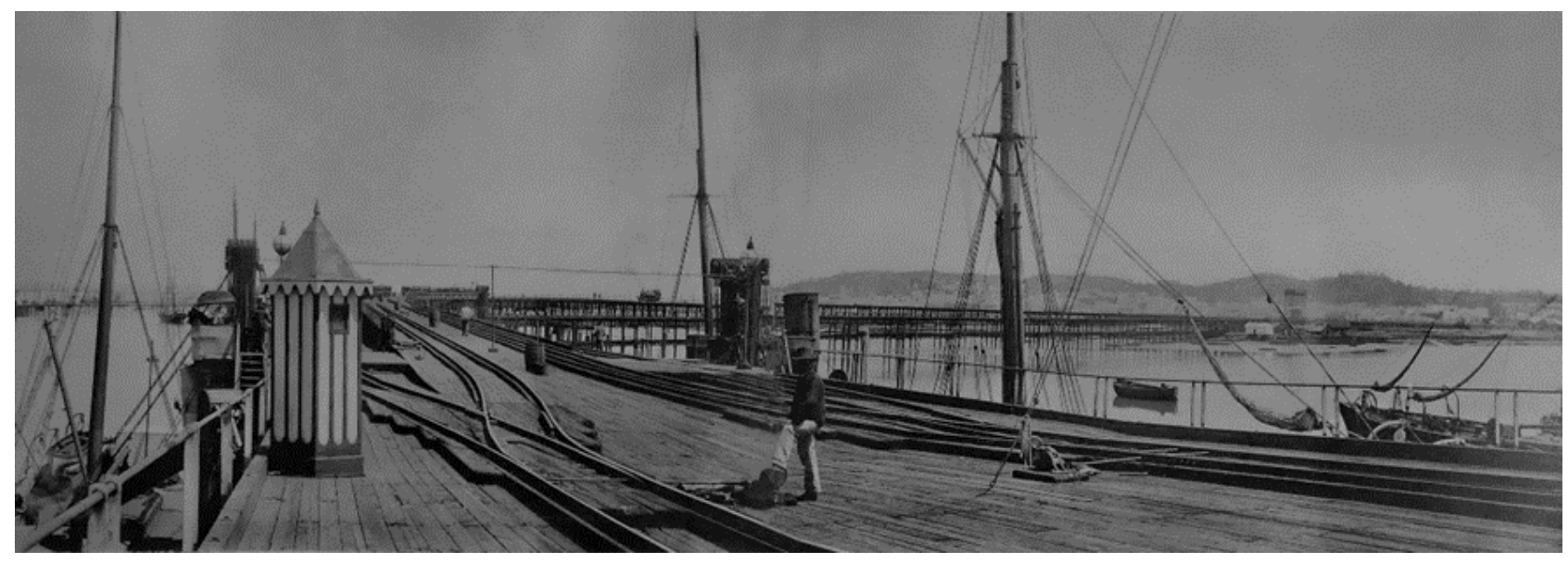

Fuente: Hauser y Menet

Fig. 1 Muelle de la RTCL en Huelva. 1892. ES.21049.AHMFRT-1

Con respecto al archivo de negativos de Laurent y Minier (1816-1892), el AHMFRT cuenta con una magnífica colección en positivos originales (postales de gran formato encuadernadas), que fue donada por el ingeniero de la RTCL, Alexander Hill, al archivo antes de su muerte. Su temática es variada y abarca desde los trabajos mineros, los pueblos y muelle de la Compañía de Rio Tinto, hasta las imágenes más populares de distintas ciudades tanto españolas como europeas, incluso detalles de monumentos artísticos y arqueológicos. De Sevilla aparece la Catedral, el Alcázar, cuadros de Murillo e Itálica, que reflejan el interés personal del ingeniero que lo llevó a este coleccionismo.

No hay ningún aspecto en relación con la minería que no esté documentado visualmente en la Fototeca. Se podría destacar también la labor de los fotógrafos locales, que intencionadamente fueron contratados por la compañía para la toma diaria de instantáneas como método de trabajo. Estaban incluidos incluso en la nómina de trabajadores estables con este cometido, como podemos atestiguar en algunos casos, como el de Tomás Atienza que trabajó sobre los años 30, realizando reportajes a diario de la Corta Atalaya. Las fotografías eran utilizadas como un instrumento más de trabajo para el estudio, análisis y evolución de los trabajos mineros, donde primaba más la intencionalidad documental que la artística. A través de ellas se pueden plantear métodos de análisis desde la arqueología visual, ya que muestran fielmente el territorio minero de entonces y a través de la mirada puede ser rescatado, y para algunos edificios e instalaciones puede ser una fuente de información de primer orden para su restauración. 
Los documentos fílmicos que están depositados en el AHMFRT merecen una mención especial por el grado de fidelidad que dan de la realidad. Tan solo son dos películas, una copia digital de una película de 1929 donada por la Rio Tinto PLC en blanco y negro, y una original en color de $35 \mathrm{~mm}$., titulada "Riotinto" de 1961, realizada por Cinecorto con depósito legal M10225. En realidad, son dos documentales, realizados con una función propagandística por las compañías que explotaban las minas en esos momentos, la RTCL y la CEMRT respectivamente. Se puede observar a través de la imagen en movimiento, como memoria audio-visual, aspectos históricos, el momento social, las costumbres, los sentimientos, la mentalidad de una época. Todo queda aprehendido en el cine como lenguaje visual atractivo, de ahí su gran valor como fuente de investigación.

\subsection{Documentos Gráficos}

$\mathrm{Al}$ igual que la fotografía, los planos son unos instrumentos idóneos para la explicación patrimonial. Actualmente la documentación de carácter gráfico está compuesta por unos 60.000 documentos aproximadamente, que incluyen mapas, planos y dibujos técnicos. Sobre Cartografía General (Grupo A), que comprende planos y mapas provinciales, municipales, comarcales, con propiedades de las Compañías mineras, etc., Cartografía específicamente minera (Grupo C), que localizan las distintas explotaciones mineras, terrenos donde se ubican las instalaciones etc., Maquinaria (Grupo D), que incluye piezas de maquinaria de todo tipo utilizada en las distintas dependencias mineras, Arquitectura (Grupo E), planos de edificios, casas, construcciones, etc., y Perfiles, Secciones, Pisos y Niveles de las minas (Grupo F).

El plano más antiguo que se conserva en la Cartoteca, como documentación asociada, fue realizado en 1828 por Joaquín Ezquerra del Bayo (AHMFRT-A00818-Dig. 10997100). Es un plano de la población y territorio de las Reales Minas de Rio-Tinto, de escala 1:10.000. El original está depositado en la Real Academia de la Historia (ICA. 88-016295). Señala con bastante precisión los accidentes geográficos como el nacimiento del río Tinto, Cerro Colorado, Salomón, San Dionisio, etc., y las instalaciones mineras y trabajos procedentes de los periodos de explotación de los asientos reales (socavones, pozos, cañerías, escoriales, restos de vías romanas, etc.). Fue levantado quizás con motivo de la cesión de la mina a favor del marqués de Remisa, que se iba a producir en 1829 por un periodo de 20 años. El plano recogería el estado de la mina antes de la cesión, pues a ella se oponía D. Fausto de Elhuyar, Director General de Minería, que previamente había informado de la necesidad de su rehabilitación (Elhuyar, 1823).

La poca rentabilidad y la alternancia en los periodos de explotación determinó nuevos replanteos de las concesiones mineras y la verificación de operaciones de deslindes, que unido a la necesidad de control de la actividad por parte del Estado, hicieron necesario la ejecución de planos, como el levantado en 1838 de nuevo por Joaquín Ezquerra del Bayo como Inspector General del Cuerpo de Ingenieros de Minas, para control de las actividades del marqués de Remisa. El original pertenece al Servicio Geográfico del Ejército (Arm. TBLA. $7^{\mathrm{a}}$ Carp. $4^{\mathrm{a}}$ núm. 536 ICA. 88-0000616), aunque en su día también fue depositada copia en el AHMFRT. Titulado Término de las Minas de Rio-Tinto. Lámina II, tiene una escala de 1:1.250, y representa los pozos activos en aquel momento, los socavones, la entrada a la cañería de cementación y las fundiciones. Se puede observar todavía un territorio menos transformado, con los cerros San Dionisio, Colorado y Salomón y la Mesa de los Pinos prácticamente intactos, y se señalan la zona de escoriales antiguos de la explotación romana y el caserío del antiguo Rio Tinto Pueblo.

Se levantaran numerosos planos sobre todo cuando se inició el proceso de venta de las minas a través de los ingenieros comisionados para su valoración, Anciola y Cossío en 1856, Gómez de Salazar en 1867, Rúa Figueroa en 1868, y la misma Comisión de ventas de las minas en 1871 encabezada por su presidente Luís de la Escosura, que realizan los primeros trabajos cartográficos antes de la llegada de los ingleses, con un alto grado de precisión en la localización y el número de las masas de yacimientos minerales. Muchos de estos planos fueron publicados después en la Revista Minera.

Desde entonces la producción de documentos cartográficos se incrementó notablemente, pero con la llegada de la RTCL en 1873 se va a convertir en una producción continua y estable como consecuencia de la creación de los departamentos técnicos para la exploración y explotación del mineral, como Geología, Topografía, Sala de dibujo, etc. RTCL contrató como asesores desde muy temprano a ingenieros españoles, como Gonzalo y Tarín (AHMFRT, Staff book $n^{\circ}$ 2. p. 124), desde 1898 hasta 1905, que se encargaron de los planes de labores con sus pertinentes 
levantamientos de planos para la inspección en Jefatura de Minas (AHMFRT, C-0469, C-01161, C-02009, C-02010, C02015, C-2016).

La documentación ha sido catalogada en Formato Marc mediante fichas catalográficas, que recogen muchos datos pertenecientes a dichos planos y mapas. Se ha efectuado una copia para seguridad y consulta en tarjetas de aperturas de $35 \mathrm{~mm}$. Para la consulta, además del catálogo editado por el Instituto de Cartografía Andaluza (ICA, 1995), tanto de los campos de descripción como para visualizar los planos digitalizados se ha instalado el programa WINISIS con la base de datos ccrecu, cuya estructura es compatible con la que ha sido catalogada la Cartoteca, CDS/ISIS. El acceso a estos documentos cartográficos es fundamental para la reconstrucción del pasado histórico y del proceso productivo minero. A través de ellos puede obtenerse información sobre el territorio y la transformación antrópica de éste, que se hace fundamental para el estudio de la Minería y de algunas ciencias como la Biología, Geografía, Urbanismo, etc.

\section{Difusión del AHMFRT. La función didáctica del patrimonio documental}

Por tanto, el AHMFRT atiende a la difusión del patrimonio documental en su triple dimensión: didáctica, divulgación e investigación histórica. Durante 2019 las consultas en el AHMFRT han sido de 915 investigadores.

En cuanto a la tipología de archivos para las prácticas didácticas, el AHMFRT es muy pertinente, ya que además de cercano a la población minera, es depositario de las fuentes primarias que contienen la historia de la sociedad que los creó. El interés de sus herederos es manifiesto, ya que la mayoría de los habitantes de una extensa comarca como la Cuenca Minera de Riotinto tiene los datos laborales registrados de sus antepasados. Es por tanto un lugar idóneo que presenta una motivación extra para los alumnos de la zona por trabajar con los valores de este tipo de patrimonio documental.

Con la planificación previa de especialistas en educación, con pedagogos y profesores, y con la ayuda de archiveros, en el AHMFRT se vienen realizando prácticas educativas, por las posibilidades que tiene, sobre todo para colegios e institutos de la comarca. Así como hemos diseñado un programa denominado, "ConTacto Documental" para acercamiento de los vecinos de los municipios del entorno al Archivo Histórico.

Durante algunos años se ha impartido en la sede del AHMFRT sesiones prácticas para el Máster de Archivística de la UNIA, y para el "Máster Cartografía y recursos estadísticos" y el "Máster de Historia", ambos de la Universidad Huelva. Es importante también desde el punto de vista didáctico la colaboración que en su día se planteó del AHMFRT con la Fundación Carlos de Amberes en el "Curso de postgrado de Especialista Universitario en Archivística" como archivo donde realizar las prácticas.

Antes de establecer programas de aprendizaje desde el archivo, es recomendable el acercamiento a la disciplina de la ciencia Archivística, y en esta tarea sí es fundamental la colaboración de los archiveros. No es fácil enfrentarse a la investigación histórica a partir de los documentos. Son muchos los condicionantes tanto metodológicos como formales que hay que superar. Para ello tanto profesores como archiveros conjuntamente, deben preparar la visita al archivo previamente, para facilitar la integración del alumno en este contexto y que no se produzca rechazo por la frustración en la visita.

El archivero debe establecer los contenidos teóricos y prácticos fundamentales del archivo que el alumno y profesor deben conocer para que no se produzca la incomprensión, la "no comunicación" del lenguaje específico del mundo archivístico (Cuenca et al., 2009). Se facilitarán, por tanto, conocimientos generales y de fácil comprensión de tipologías documentales, sistema de clasificación documental, cuadros de clasificación, etc. Se establecerán también planes, estrategias de conocimiento, adaptados a las capacidades cognitivas del alumno. De forma que éste aprenda a "averiguar" y a "descubrir" con distintos grados de dificultad según el nivel académico. Se trata por tanto de aprender desde las fuentes primarias a partir del análisis personal de éstas (Rey, 2004).

Para ello deben ser elegidos como instrumentos didácticos los documentos que menos dificultades presenten, para establecer el necesario encuentro entre documentos y alumnos, con temáticas interesantes para ellos, cercanas, y si puede ser divertidas. El archivero debe seleccionar los documentos con mayor valor pedagógico y contenidos, 
El patrimonio documental como instrumento indispensable para la descripción disciplinar del patrimonio. Algunos ejemplos de tipologías en el Archivo Histórico Minero de Fundación Río Tinto (es. 21049.ahmfrt)

establecer su presentación, y planificar con el docente las actividades a desarrollar según el tipo de alumnos a los que vayan dirigidas las actividades y el método didáctico (Vela, 2002).

En los archivos contemporáneos, como es el caso, el lenguaje es el mismo y no se necesita el conocimiento paleográfico. Es recomendable que trabajen a partir del documento original, y de no ser posible al menos a partir de una copia facsimilar, igual de atractivos, y no desde la trascripción, ya que la manipulación de documentos originales le da un valor añadido. Se trata de eliminar miedos y barreras, cambiar la percepción tradicional de coto privado y dar una nueva imagen aperturista de los archivos.

El documento como un instrumento didáctico debe salir de la concepción que se le tiene atribuida hasta ahora como recurso para el estudio de unos pocos investigadores, y mostrar toda su carga didáctica, también como revelador de gran parte y tipos de patrimonios. Saber enseñar el patrimonio a partir de los documentos es una tarea que encajaría perfectamente en el currículo oficial de muchas asignaturas, y no sólo de las ciencias sociales. El patrimonio debe ser contemplado interdisciplinarmente, por lo que las actividades específicas con documentos es un recurso transversal excelente. Así pues, documento es nexo de la dualidad para la enseñanza de patrimonio entre las Ciencias Sociales y Experimentales.

Los archivos son garantes de la difusión patrimonial. Los valores patrimoniales planteados deben ser asumidos y aceptados por el grupo como parte de su propia identidad, es decir, reconocerse en el patrimonio, para que sea legitimado socialmente dentro de una comunidad (Albert, 2011). En estos discursos de identidad colectiva debe prevalecer siempre el respeto a la diferencia, a la existencia de otras culturas, convivir con la multiculturalidad como proceso democrático, sin manipulaciones ideológicas que lleven al alumno a concepciones equivocadas, no pertinentes en cualquier didáctica de patrimonio. El patrimonio debe partir de valores fundamentales, como igualdad, solidaridad, respeto, esfuerzo, trabajo, etc.

La escasa información sobre la acelerada degradación de los ecosistemas, el agotamiento de recursos naturales, la pérdida de diversidad biológica y cultural, y los insostenibles desequilibrios entre grupos humanos, pueden ser abordados desde y con documentos de archivos (con diversas clases de documentos como los textuales, en imagen, cartográficos, etc.), que conlleven además de la información curricular estos mensajes de respeto al planeta Tierra. Se debe hacer partícipe al propio usuario en el ejercicio con el trabajo documental, de forma que haya opción de influir y participar en la construcción de un futuro alternativo mejor, donde respetemos el medio ambiente y las creaciones humanas como patrimonio imprescindible de obligada conservación.

Esta problemática está muy presente en las cuencas mineras, por lo que desde el AHMFRT se podría plantear trabajar estos aspectos de contaminación medioambiental, ocasionados históricamente por los distintos sistemas de explotación utilizados para la explotación de mineral. Es aprender la historia con ejemplificaciones presentes y en relación con el patrimonio, ya que el conocimiento histórico es útil para la solución de los problemas presentes y para la comprensión crítica de nuestro pasado como base para la interpretación simbólica de los elementos patrimoniales del pasado, entendidos y asumidos como recursos identitarios del presente (Estepa, 2001).

Patrimonio e identidad van de la mano en las sociedades con motivaciones históricas comunes. Los elementos patrimoniales son susceptibles de reconstruir la historia de cada época, llevan implícito en sí el conocimiento del pasado de una determinada sociedad y de los periodos que la crearon (Tribó, 2005). Entendemos la enseñanza del patrimonio histórico como fomento de una conciencia solidaria, de preservar identidades, de conservar las manifestaciones culturales en un contexto determinado frente a la globalización, estandarización, universalismo, es decir formar desde el pasado un espíritu crítico respetando las singularidades y el pluralismo, lo cercano y lo lejano, lo propio y lo ajeno, el yo y los otros, y todo ello a través del conocimiento del patrimonio cultural.

\section{Conclusiones}

En definitiva, a través de los documentos se puede enseñar tanto patrimonio mueble, como inmueble, material como inmaterial, ya que son muchas las series de documentos para la comprensión del patrimonio cultural, y son un vehículo fundamental para el conocimiento histórico desde la objetividad. 
Además del valor instrumental de la transmisión de la información, los documentos tienen un valor patrimonial como testimonio material de la industria. El uso de los documentos de Archivos es de vital importancia para la investigación histórica y como recurso para el desarrollo de proyectos con perspectivas didácticas, así como para el conocimiento de la ciudadana del patrimonio cultural, ya que puede incidir directamente en el estudio del resto de los "patrimonios", convirtiéndose en un instrumento transversal fundamental para el estudio y desarrollo de activos patrimoniales, tanto conservados como no. El patrimonio documental se debe convertir en un instrumento indispensable para el conocimiento de un patrimonio minero "olvidado", y del que apenas se conservan algunas huellas marcadas en el paisaje.

Por tanto, la conservación y la Didáctica del patrimonio es una obligación de todos los gestores culturales, tanto, públicos como privados, así como es obligación de la comunidad educativa de incluirlos permanentemente en los currículos oficiales de la enseñanza, ya que representa la revalorización del pasado y los recursos del futuro.

\section{Referencias}

Albert Fugueras, R. (2011). Difusión y acción cultural. En J. R. Cruz Mundet (Dir.), Administración de documentos y archivos. Textos fundamentales (pp. 773-486). Madrid: Coord. de Asociaciones de Archiveros y Gestores de Documentos.

Cuenca, J. M., y Martín, M. (2009). La comunicación del patrimonio desde propuestas de educación no formal e informal. En J. M. González y J. M. Cuenca (Eds.), La musealización del patrimonio (pp. 35-46). Huelva: Universidad de Huelva.

Elhuyar, F. (1823). Relación de las minas de Rio Tinto. En Biblioteca Instituto Geológico Minero de España. Manuscrito facsimilar. R.4988.

Estepa, J. (2001). El patrimonio en la Didáctica de las Ciencias Sociales: obstáculos y propuestas para su tratamiento en el aula. Íber: Didáctica de las Ciencias Sociales, Geografia e Historia, 30, 93-105.

Instituto de Cartografía de Andalucía. (1995). Catálogo de Cartografía Histórica de Huelva. Sevilla: Consejería de Obras Públicas y Transportes.

Jiménez Barrientos, J. C. (1997). El patrimonio industrial. Algunas consideraciones relativas a su concepto y significado. PH: Boletín del Instituto Andaluz del Patrimonio Histórico, 21, 99-105.

Pérez López, J. M. (2003). Experiencia de organización de un archivo de empresa. El Archivo Minero de Fundación Rio Tinto. En ANABAD, 53:1, 9-24.

Pérez López, J. M. (2008). Guía e instrumentos de descripción del Archivo Histórico Minero. Fundación Río Tinto. Consejería de Cultura y Fundación Río Tinto.

Rey De La Peñas, R. (Dir.). (2004). Aprender y enseñar con el archivo. Huelva: Diputación Provincial.

Sobrino, J. (1996). Arquitectura Industrial en España, 1830-1990. Madrid: Cátedra.

Tribó, G. (2005). Enseñar a pensar históricamente. Los archivos y las fuentes documentales en la enseñanza de la historia. Barcelona: ICE-Horsori, 19.

Vela, S. (2002). Archivos y Didáctica: un estado de la cuestión. Íber: Didáctica de las Ciencias Sociales, Geografia e Historia. Monografía sobre los archivos en la Didáctica de las Ciencias Sociales, 34, 27-36. 